\title{
Lamina specific loss of inhibition may lead to distinct neuropathic manifestations: a computational modeling approach
}

\author{
Erick Javier Argüello Prada*, Ricardo José Silva Bustillos, Mónica Karel Huerta, \\ Antonio D’Alessandro Martínez
}

\begin{abstract}
Introduction: It has been reported that inhibitory control at the superficial dorsal horn (SDH) can act in a regionally distinct manner, which suggests that regionally specific subpopulations of SDH inhibitory neurons may prevent one specific neuropathic condition. Methods: In an attempt to address this issue, we provide an alternative approach by integrating neuroanatomical information provided by different studies to construct a network-model of the SDH. We use Neuroids to simulate each neuron included in that model by adapting available experimental evidence. Results: Simulations suggest that the maintenance of the proper level of pain sensitivity may be attributed to lamina II inhibitory neurons and, therefore, hyperalgesia may be elicited by suppression of the inhibitory tone at that lamina. In contrast, lamina III inhibitory neurons are more likely to be responsible for keeping the nociceptive pathway from the mechanoreceptive pathway, so loss of inhibitory control in that region may result in allodynia. The SDH network-model is also able to replicate non-linearities associated to pain processing, such as $A \beta$-fiber mediated analgesia and frequency-dependent increase of the neural response. Discussion: By incorporating biophysical accuracy and newer experimental evidence, the SDH network-model may become a valuable tool for assessing the contribution of specific SDH connectivity patterns to noxious transmission in both physiological and pathological conditions.
\end{abstract}

Keywords: Computational pain modeling, Inhibitory control, Superficial dorsal horn circuit, Network model.

\section{Introduction}

Over the last two decades, multiple approaches have been used in an effort to delineate the neural circuitry of the superficial dorsal horn (SDH), given its importance as the first node in the pain pathway (Millán, 1999; Todd, 2010). Lu and co-workers identified an inhibitory ( $\mathrm{Lu}$ and Perl, 2003), an excitatory (Lu and Perl, 2005) and a normally silent pathway (Lu et al., 2013) by performing "paired" patch clamp recordings on SDH neurons in a slice preparation. Zheng et al. (2010) reported the presence of a subset of inhibitory central cells which interact reciprocally with islet cells in transgenic mice where the green fluorescent protein (GFP) gene was inserted, such that the GFP expression was restricted to that subpopulation of neurons (Tamamaki et al., 2003). An alternative technique in which whole-cell patch-clamp recording in the slice preparation is used to record postsynaptic responses to brief light pulses $(<1 \mathrm{~ms})$, capable of activating a caged (i.e., molecularly inactive and light sensitive) form of glutamate (Callaway and Katz, 1993), has been recently used to map the locations of neurons that project locally to a single identified neuron in the SDH (Kato et al., 2009; Kosugi et al., 2013). This fragmentary evidence has been summarized by several authors (Graham et al.,
2007; Todd, 2010; Zeilhofer et al., 2012), but the precise contribution of those interactions to noxious processing, especially in pathological conditions, remains unclear.

Neuropathic pain is a neural disease state developed by a series of functional and structural alterations of the somatosensory nervous system, mostly maladaptive (Costigan et al., 2009). These alterations involve plastic changes that may result in abnormal pain sensations, such as hyperalgesia (increased pain sensitivity) and allodynia (pain as a response to non-nociceptive stimuli) (Sandkühler, 2009). A phenotypic change from nociceptive specific to multimodal responsiveness of lamina I projection neurons has been proposed as an explanation for tactile allodynia (Keller et al., 2007). Nevertheless, the activation via disinhibition of preexisting connections between the low-threshold (LT) mechanoreceptive pathway and the nociceptive pathway appears to be one of the most consolidated hypotheses. Indeed, several studies based on pharmacological blockade of gamma-aminobutiryc acid-ergic (GABAergic) and/or glycinergic (Gly) synaptic transmission in the spinal dorsal horn (DH) have revealed a normally 
silent (i.e., under strong inhibitory control) linkage that allows the $\mathrm{A} \beta$-fiber inputs to activate the lamina I projection neurons after nerve injury (Baba et al., 2003; Lu et al., 2013; Miraucourt et al., 2007). Inhibitory neurons constitute approximately $28-46 \%$ and $24-38 \%$ of the neurons in laminae I-III of rat (Todd and Sullivan, 1990) and mouse (Polgár et al., 2013) spinal cord, respectively. These cells are mainly GABA-immunoreactive and many of them exhibit also high levels of glycine-immunoreactivity, thereby suggesting that a significant proportion of inhibitory neurons co-release GABA and glycine. On the other hand, there is evidence demonstrating that inhibition can act in a regionally distinct manner in the spinal cord of some rodents (Takazawa and MacDermott, 2010a), which in turn suggests that regionally specific loss of inhibition (local disinhibition) may lead to different neuropathic manifestations. In order to address this issue, the present study aims: (1) to construct a network-model of the SDH that acknowledges and integrates neuroanatomical information provided by different experimental studies, (2) to evaluate how useful is the Neuroid (Prada et al., 2012) in modeling each neuron included in the model, (3) to analyze the response of the model after simulating regionally specific changes in inhibitory control, and (4) to stimulate further research in this direction.

\section{Methods}

\section{A network-model of the SDH}

Table 1 summarizes some of the SDH connectivity patterns that several authors have elucidated by using the aforementioned techniques. Several assumptions have also been made to ease the design. First, since the population of neurons in lamina I receiving input from lamina II vertical cells included some that contribute to rostrally directed pathways (Lu and Perl, 2005), the neuron in lamina I could be viewed as a projection neuron. Second, although it was suggested that a subset of inhibitory central cells in lamina II that reciprocally interacts with islet cells also receives input from unmyelinated fibers particularly sensitive to cooling, such that cooling stimulation usually suppresses noxious transmission (Zheng et al., 2010), we arranged that the inhibitory central cell receives input from the $\mathrm{A} \beta$-fiber in agreement with a previous study

Table 1. Neuron connectivity at the superficial dorsal horn. GFP: green fluorescent protein; SG: substantia gelatinosa.

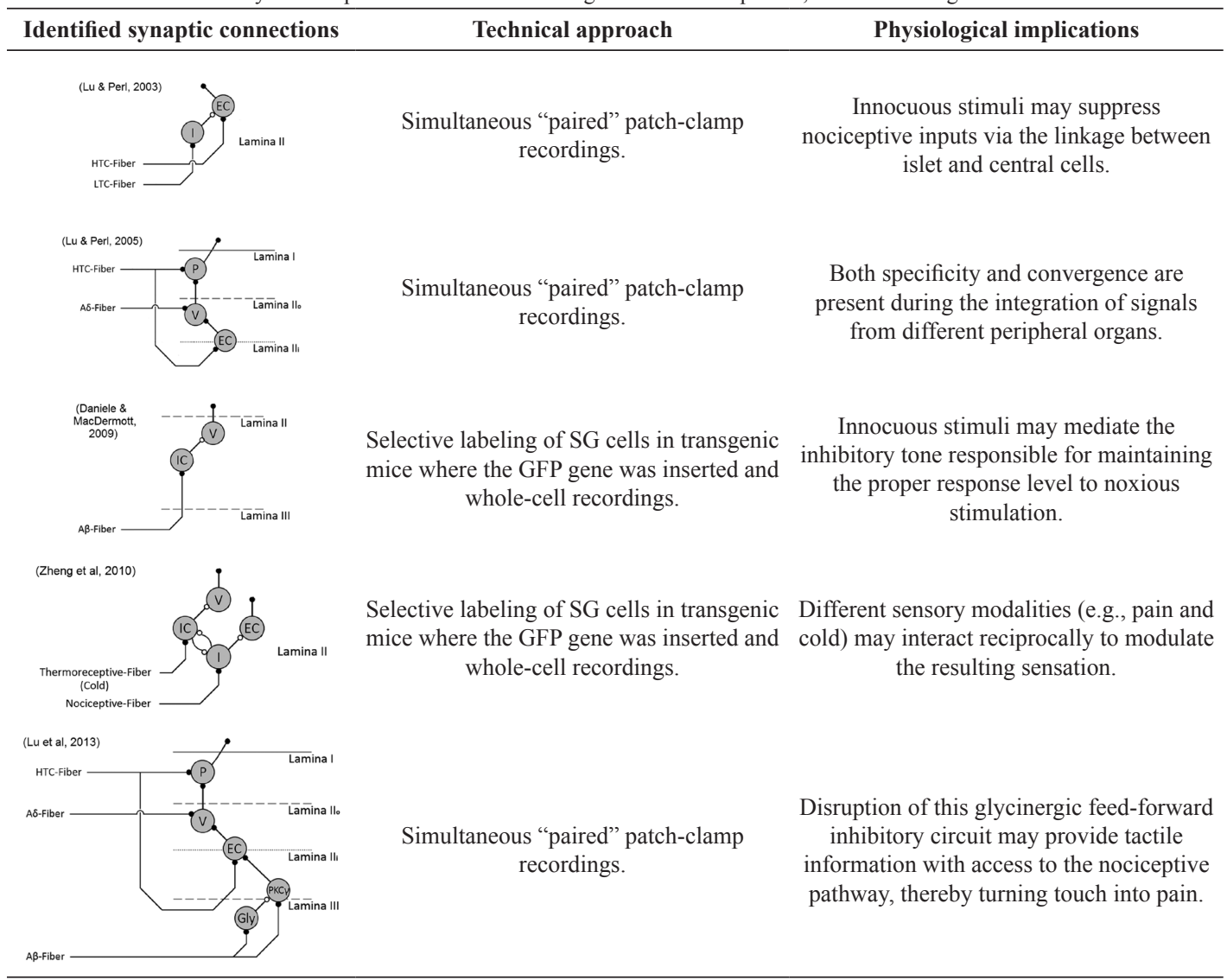


(Daniele and MacDermott, 2009). Third, inhibitory neurons of lamina II receive input from both LT and high-threshold (HT) primary afferents (Daniele and MacDermott, 2009), but we considered only the LT drive from A $\beta$-fibers. Fourth, the excitatory central cell reported by Lu and Perl (2005) was assumed to be tonic instead of transient (it actually fires rapidly but briefly to sustained depolarizations). The schematic representation of the network-model of the SDH circuitry, which henceforth will be referred to as the SDH network-model, is depicted in Figure 1.

\section{Single-cell modeling}

By assuming that information transmitted across the nervous system is encoded in the neurons' firing frequency, similarities between Pulse Frequency
Modulation (PFM) and the action potential generation process have been pointed out by several authors (Bayly, 1968; Horch and Dhillon, 2004; Rieke et al., 1997). With that in mind, the neuron's output $y(t)$ can be modeled as a train of equally spaced impulses given by:

$$
y(t)=\sum_{n=0}^{\infty} \delta\left(t-\frac{n \beta T}{s(t)-u m b r}\right) \text { if } s(t)>u m b r
$$

In the equation above, $\delta(\cdot)$ represents a single spike, $T$ is the time between two consecutive spikes and denotes the absolute refractory period of the axon, $u m b r$ is the activation threshold and $\beta$ is a proportionality constant that controls the slope of the Neuroid's frequency-intensity (FI) curve

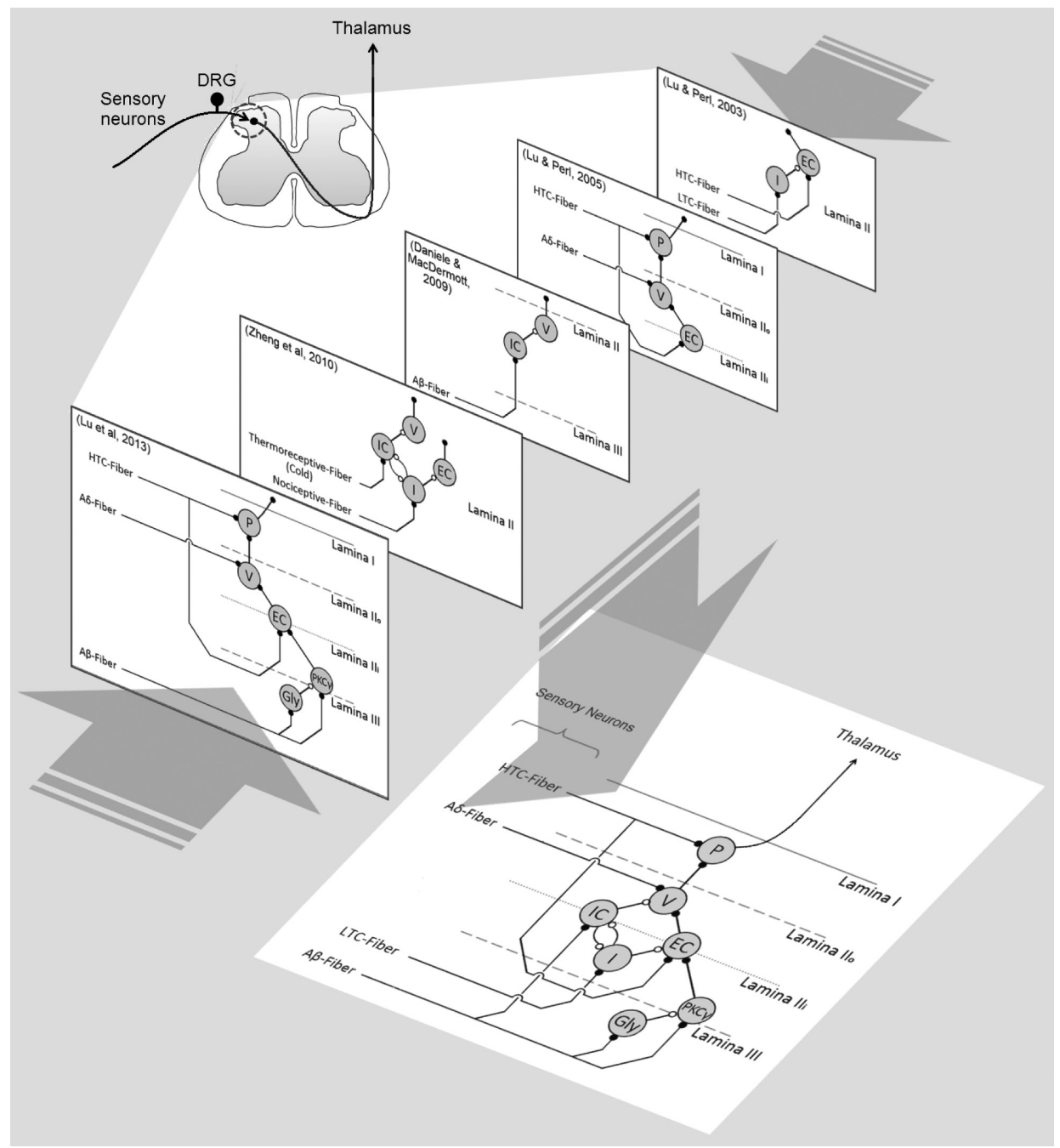

Figure 1. Fragmentary neuroanatomical evidence (black bordered panels) is combined to elaborate an alternative representation of the superficial dorsal horn circuitry (bottom panel). DRG, dorsal root ganglion; EC, excitatory central cell; Gly, glycinergic neuron; HTC-fiber, high-threshold C-fiber; I, islet cell; IC, inhibitory central cell; LTC-fiber, low-threshold C-fiber; P, lamina I projection neuron; PKC $\gamma$, neuron expressing the gamma-isoform of protein kinase $\mathrm{C}$; V, vertical cell; $\bullet$, excitatory synapse; $\circ$, inhibitory synapse. 
(i.e., the firing frequency as a function of the stimulus intensity). The triggering event, designated by $s(t)$, can be written as:

$$
s(t)=\sum_{j=1}^{m} w_{j} x_{j}
$$

where $x_{1}, x_{2}, \ldots, x_{m}$ are the input signals (often assumed as normalized and dimensionless) and $w_{1}, w_{2}, \ldots, w_{m}$ are their corresponding synaptic weights. The terms $u m b r, \beta$ and $s(t)$ are dimensionless, whereas $T$ is given in ms. As can be seen from Equation 1, the division by zero is avoided because $s(t)$ exceeds the activation threshold (umbr). The Neuroid is able to represent normally silent and tonically active neurons, and it also provides an amplitude-discrete version of the triggering signal $s(t)$, named $n t \_o u t(t)$. The latter is possible by adjusting two additional parameters: $K$, a dimensionless proportionality constant to control the amplitude of the output, and maxcount, a time parameter to extend the output signal by several milliseconds after the last spike before dropping to the resting value.

Several studies have quantified the response properties of different types of neurons to depolarizing/ hyperpolarizing current injections as well as to mechanical/thermal stimuli using both in vitro and in vivo preparations (Baba et al., 1999; Cain et al., 2001; Graham et al., 2004; Ruscheweyh and Sandkühler, 2002; Schoffnegger et al., 2008; Slugg et al., 2000; 2004). Based on the available experimental evidence, functional features of primary afferent fibers and dorsal horn neurons have been pointed out as follows:

1. A $\beta$-fibers and $\mathrm{C}$-fibers exhibit the lowest and the highest median activation thresholds, respectively, in response to both current injections (Baba et al., 1999; Schoffnegger et al., 2008) and mechanical stimuli (Cain et al., 2001) (i.e., threshold ${ }_{A \beta}<$ threshold $_{A \delta}<$ threshold $_{C}$ ); however, some studies have reported that threshold $_{\mathrm{C}}<$ threshold $_{\mathrm{A} \hat{\delta}}$ when forced-controlled stimulation protocols were used (Slugg et al., 2000; 2004).

2. The slope of the FI curve for the A-fibers was significantly steeper than that for the C-fibers, and the total response was also greater, although this characterization was restricted to nociceptive primary afferents (Slugg et al., 2000; 2004).

3. The responses of tonic firing neurons in lamina I express smoother slopes and, therefore, lower firing frequencies than those for tonic firing neurons in deeper laminae (Ruscheweyh and Sandkühler, 2002).
4. It has been difficult to find direct relations between the current-induced firing patterns and peripherally evoked responses in SDH neurons, probably because current injections have more impact on somatic than dendritic conductances whereas dendritic connections may be the major source of depolarizing drive evoked by primary afferent activation (Graham et al., 2004).

As performed in an earlier study (Prada and Bustillos, 2013), we reconstructed the FI curves $(f(i))$ of primary afferent and DH neurons from experimental data after normalizing stimulation ranges $(0-200 \mathrm{mN}$ for primary afferents; $0-350 \mathrm{pA}$ for $\mathrm{DH}$ neurons), and then, we found the linear equation that best fitted to those results. Thus, for each type of neuron, one can approximate the FI curve to:

$f(i)=m i+b$

where $m$ denotes the slope of that curve. The corresponding value of $\beta$ will be given by:

$\beta=607.65 m^{-1.055}$

To model primary afferents it was assumed that $\beta_{\mathrm{A} \beta}<\beta_{\mathrm{A} \delta}<\beta_{\mathrm{C}}$ since, in agreement with experimental observations (Slugg et al., 2000; 2004), $m_{\mathrm{A} \beta}>m_{\mathrm{A} \delta}>m_{\mathrm{C}}$. For DH neurons, the deeper the location of the cell, the steeper the slope of its FI curve (Ruscheweyh and Sandkühler, 2002) and, therefore, the lower its corresponding value of $\beta$. Thus, we chose $\beta_{\text {Lamina I }}$ $>\beta_{\text {Lamina II }}>\beta_{\text {Deeper Laminae }}$. From the results obtained by the groups of Baba et al. (1999), Cain et al. (2001) and Schoffnegger et al. (2008), it can be seen that threshold ${ }_{\mathrm{A} \delta} \approx 2$ threshold $_{\mathrm{A} \beta}$ and threshold $\mathrm{C}$ $\approx 10$ threshold $_{A \beta}$. We selected threshold ${ }_{A \beta}=2.1 \mathrm{mN}$ (Cain et al., 2001) to find threshold ${ }_{\mathrm{A} \delta}$ and threshold ${ }_{\mathrm{C}}$ and the corresponding normalized values were used to set the parameter umbr for each Neuroid representing a specific primary afferent type. The low-threshold C-fiber (LTC-fiber) was built by combining the A $\beta$-fiber median threshold and the high-threshold C-fiber (HTC-fiber) FI curve slope (see Table 2). For Neuroids representing DH neurons, threshold values were assumed lower than those for primary afferents. Each element of the SDH network-model was simulated in LabView 2013 (running on Acer Travelmate portable PC) with $T=2 \mathrm{~ms}$ and maxcount $=32 \mathrm{~ms}$. The values of $K_{r}$ for each Neuroid were chosen such that we could obtain an output signal as similar as possible to the input signal, as done in previous implementations (Prada et al., 2013; Prada and Bustillos, 2013). 
Table 2. Parameters for the model of the superficial dorsal horn circuitry.

\begin{tabular}{|c|c|c|c|c|c|c|c|c|c|c|c|}
\hline & \multicolumn{4}{|c|}{ Primary afferents } & \multicolumn{7}{|c|}{ DH neurons } \\
\hline & $\mathbf{A} \boldsymbol{\beta}$ & $\mathbf{A} \boldsymbol{\delta}$ & LTC & HTC & Gly & PKC $\gamma$ & I & EC & IC & $\mathbf{V}$ & $\mathbf{P}$ \\
\hline$u m b r$ & $0.011 \S$ & $0.052 \S$ & $0.011 \S$ & $0.122 \S$ & $0.006 \ddagger$ & $0.006 \%$ & $0.006 t$ & $0.006 \ddagger$ & $0.006 \ddagger$ & $0.006 t$ & $0.006 t$ \\
\hline$\beta$ & 12.14 & 29.08 & 180.1 & 180.1 & 5.660 & 6.925 & 6.925 & 8.190 & 8.190 & 9.455 & 10.72 \\
\hline $\boldsymbol{K} \boldsymbol{r}$ & 2.1 & 6.1 & 31.1 & 35.1 & 4.1 & 5.1 & 5.1 & 6.1 & 6.1 & 7.1 & 8.1 \\
\hline
\end{tabular}

§: Normalized threshold value from 0-200 mN (Cain et al, 2001). *: Normalized threshold value from 0-350 pA (Ruscheweyh and Sandkühler, 2002). For all Neuroids, T and maxcount were set at 2 and $32 \mathrm{~ms}$, respectively. The values of $\beta$ were obtained from $607.65 \mathrm{~m}-1.055$, where $\mathrm{m}$ is the slope of the line that best fits the experimental results reported by Slugg et al. (2000) (primary afferents) and Ruscheweyh and Sandkühler (2002) (DH neurons).

\section{Putting the pieces together}

We chose $w_{j}=1$ and -1 to represent respectively postsynaptic facilitation and inhibition (Equation 2). Multiple slide controls were included to reduce the inhibitory influence exerted by the Neuroids representing SDH inhibitory neurons (labeled as I: islet cell; IC: inhibitory central cell; and Gly: glycinergic neuron). Waveform charts were added to visualize the input signal as well as the response of the Neuroids used for modeling primary afferents and the lamina I projection neuron.

\section{Network-model inputs}

Several waveforms were used as inputs and they ranged from rectangular pulses with progressive increases (from 0 to $400 \mathrm{mN} ; 0.175$-s steps of $40 \mathrm{mN}$ ) to cosine shaped curves of order 8 , which have been used as the wind-up impulse train by several authors (Britton et al., 1996; Farajidavar et al., 2008; Prince et al., 2004). We plotted the response of the lamina I projection-Neuroid (P-Neuroid) while two sets of three 2-s rectangular pulses with different amplitudes were simultaneously applied to all Neuroids representing primary afferents: a first set of pulses whose amplitudes lied in the range able to activate the P-Neuroid (180, 240 and $320 \mathrm{mN})$, and a second set of pulses with amplitudes able to activate only the A $\beta$ - and LTC-Neuroids (3.5, 6 and $9 \mathrm{mN}$ ). With slide controls, it was possible to simulate local disinhibition during "noxious" and "non-noxious" sustained stimulation by increasing (doubling) the value of $\beta$ for each inhibitory Neuroid, one at a time. Separate stimulation of A $\beta$ - and HTC-labeled Neuroids included constant HTC-fiber input with variable $A \beta$-fiber input:

$x_{\text {HTC }}(t)=100 m N \quad 0 \leq x_{A \beta}(t) \leq 120 m N$

and wind-up stimulation:

$$
\begin{aligned}
& x_{H T C}(t)=100 \operatorname{Cos}^{8}(2 \pi f t) m N \\
& x_{A \beta}(t)=0.1 x_{c}(t)
\end{aligned}
$$

as done several years ago by Britton et al. (1996) (see experiments (i) and (iii)). The frequency ( $f$ ) of the wind-up impulse train was adjusted to $1,2,5$ and $10 \mathrm{~Hz}$, in order to observe any change in the response of the P-Neuroid as a function of the frequency stimulation.

\section{Results}

\section{The Neuroid provides a good representation of some, but not all, neurons included in the SDH network-model}

The response of the A $\delta$-, HTC-, P-, and Glylabeled Neuroids were compared to available data from nociceptive primary afferents (Slugg et al., 2000) and DH neurons (Ruscheweyh and Sandkühler, 2002). Upper panels show the number of action potentials fired by an $\mathrm{A} \delta$-fiber (Figure 2a), a C-fiber (Figure 2d), and their corresponding models (Figures $2 \mathrm{~b}, \mathrm{e}$ ), as a response to 3 -s stimuli ranging from 20 to $100 \mathrm{mN}$. The FI curve of the A $\delta$-labeled Neuroid matched the experimental curve (see Figure 2c). On the other hand, the FI curve of the HTC-labeled Neuroid increased monotonically (Figure 2f) instead of reaching a plateau as observed in experiments, and the total response of the model was lower than that for the C-fiber. We also show the number of action potentials fired by a tonic-firing neuron from lamina I (Figure 2g), a tonic-firing neuron from deeper laminae (Figure 2i), and their corresponding models (P- and Gly-labeled Neuroids, respectively) (Figures $2 \mathrm{~h}, \mathrm{j}$ ), as a response to 1 -s current injection pulses ranging from 0 to $350 \mathrm{pA}$. Figures $2 \mathrm{k}, 1$ show the FI curves of DH tonic-firing neurons from lamina I and deeper laminae, respectively, and their computational counterparts (superimposed).

\section{The response of the SDH network-model to gradual increases of the stimulus amplitude}

Figures $3 \mathrm{a}, \mathrm{b}$ depict respectively the schematic representation of the simulation (co-stimulation regime) and the response of the Neuroids used for modeling primary afferents and the lamina I projection neuron to progressive increases of the input signal, which ranged 
(a)

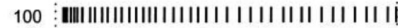

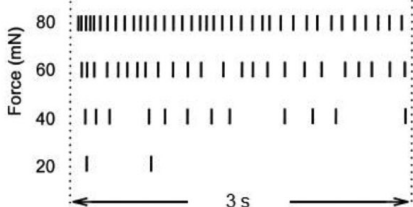

(d)

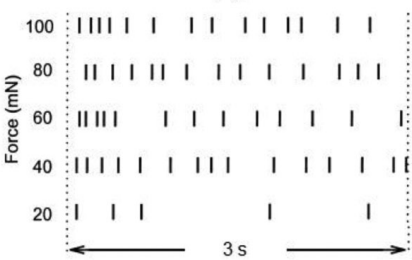

(g)
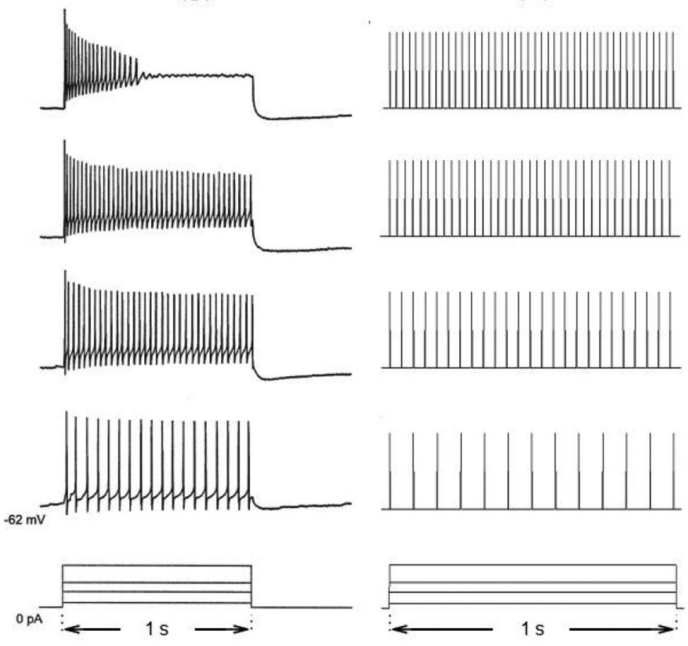

(k)

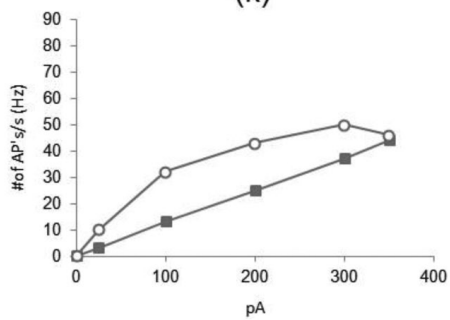

(h) (b)

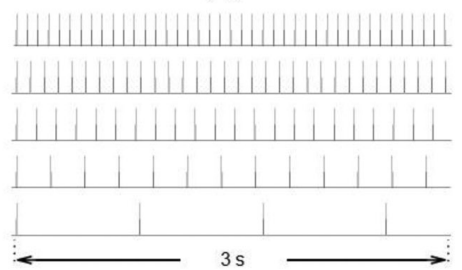

(e)

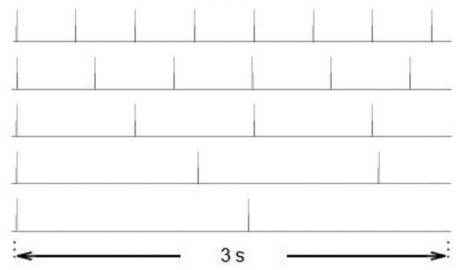

(i)
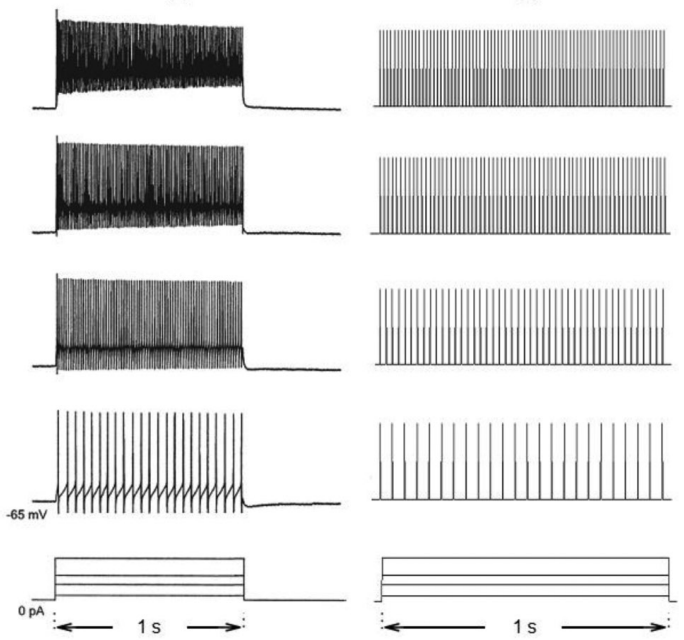

(I)

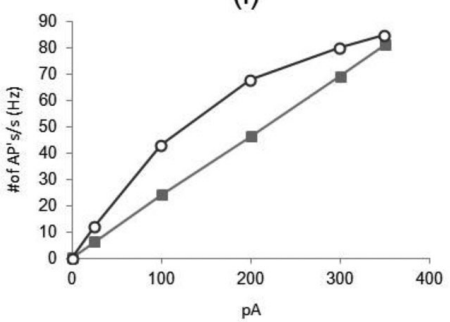

Figure 2. Neuroids representing primary afferents and dorsal horn (DH) neurons are compared with experimental data. (a) Response of a typical nociceptive A-fiber to stimuli ranging from 20 to $100 \mathrm{mN}$ (1 vertical segment $=1$ action potential). (b) Response of the A $\delta$-Neuroid to the same stimuli. (c) The FI (frequency-intensity) curve of the model (closed squares) matches the experimental curve (open circles). (d) Response of a typical nociceptive C-fiber to stimuli ranging from 20 to $100 \mathrm{mN}$. (e) Response of the high-threshold C-Neuroid (HTC-Neuroid) to the same stimuli. (f) The FI curve of the model (closed squares) does not match the experimental curve (open circles), but it approximates to the average response of C-fiber nociceptors across the receptive field (Slugg et al, 2004). (g) Response of a tonic firing neuron from lamina I to selected values of 1-s depolarizing current injections. (h) Response of the lamina I projection-Neuroid (P-Neuroid) to the same stimuli. (i) Response of a tonic firing neuron from deeper laminae to selected values of 1-s depolarizing current injections. (j) Response of the glycinergic-Neuroid (Gly-Neuroid) (lamina III) to the same stimuli. (k) and (1) The FI curves of the P- and Gly-Neuroids (closed squares), which respectively represent neurons from lamina I and deeper lamina, do not match their biological counterparts (open circles), although the models are able to preserve the relationship between the firing frequencies exhibited by DH neurons (i.e., $f_{\text {deeper laminae neurons }}>f_{\text {lamina Ineurons, }}$ in agreement with observations made by Ruscheweyh and Sandkühler (2002)). (a) and (d) were adapted from Slugg et al. (2000). (g), (i), (k) and (1) were adapted from Ruscheweyh and Sandkühler (2002). 
from 0 to $400 \mathrm{mN}$ (40 $\mathrm{mN}$ step; 0.175 -s duration). The P-Neuroid activated when the circuit input reached $160 \mathrm{mN}$, its firing frequency raised quickly at higher input values and it also continued firing after the cessation of stimulus. As shown in Figure 3c, the total response of the P-Neuroid as a function of the stimulus intensity increased monotonically.

\section{A selective diminishing of the inhibitory control yields different responses}

Figure 4 illustrates how regionally specific reduction of the inhibitory tone evokes different responses on the P-Neuroid to sustained stimulation. As can be seen in Figure 4a, the P-Neuroid increased its firing frequency during "noxious" sustained stimulation $(180 \mathrm{mN})$ when the influence exerted by IC- and Gly-Neuroids was decreased by approximately $50 \%$ ( $7^{\text {th }}$ and $9^{\text {th }}$ panels from the top). On the contrary, the response of the P-Neuroid decreased as a result of reduced inhibitory tone provided by the I-Neuroid ( $8^{\text {th }}$ panel). Similar results were observed at 240 and $320 \mathrm{mN}$ (see Figure 4c).

While all the Neuroids representing DH inhibitory neurons were operating at $100 \%$ and even after reducing the inhibitory tone provided by the I- and IC-Neuroids, one at a time, no response was noted on the P-Neuroid to "non-noxious" sustained stimulation $(6 \mathrm{mN})\left(6^{\text {th }}\right.$ to $8^{\text {th }}$ panels from Figure $\left.4 \mathrm{~b}\right)$. Only by reducing the influence exerted by the Gly-Neuroid it was possible to activate the P-Neuroid ( $9^{\text {th }}$ panel). Similar results were obtained at 3.5 and $9 \mathrm{mN}$ (see Figure 4d).

\section{The SDH network model captured some non-linearities involved in noxious processing}

Figure 5a depicts a schematic representation of selective stimulation. As shown in Figure 5b, the firing frequency of the P-Neuroid decreased slightly $\left(4^{\text {th }}\right.$ panel) as a response to gradual increases of the $\mathrm{A} \beta$-Neuroid input, which ranged from 0 to $120 \mathrm{mN}$ (0.8-s steps of $40 \mathrm{mN})$, with constant HTC-Neuroid input (a 3.2-s pulse of $100 \mathrm{mN}$ ). However, the response of the P-Neuroid ceased to decrease for $A \beta$-Neuroid inputs greater than $80 \mathrm{mN}$ (Figure 5c), which suggests that the $A \beta$-mediated analgesia only occurs for a limited range of mechanical intensities.

Finally, a frequency varying cosine shaped curve of order 8 was used at four different frequencies with 5-s intervals of no stimulation between two frequency values. As the frequency of stimulation increased, the number of pulses fired by the P-Neuroid increased vigorously (see $4^{\text {th }}$ panel of Figure $6 a$ ), thereby resembling a frequency-dependent response potentiation. On the other hand, our results differ from those experimentally obtained by Schouenborg (1984) (see Figure 6b). (a)

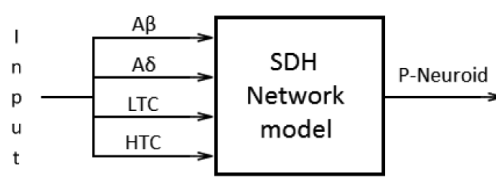

(c)

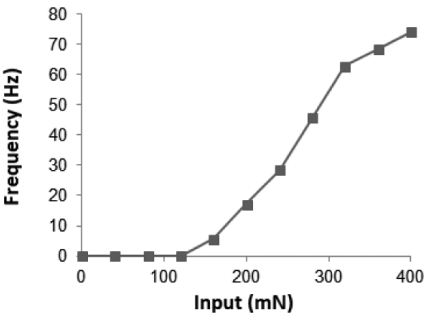

(b)

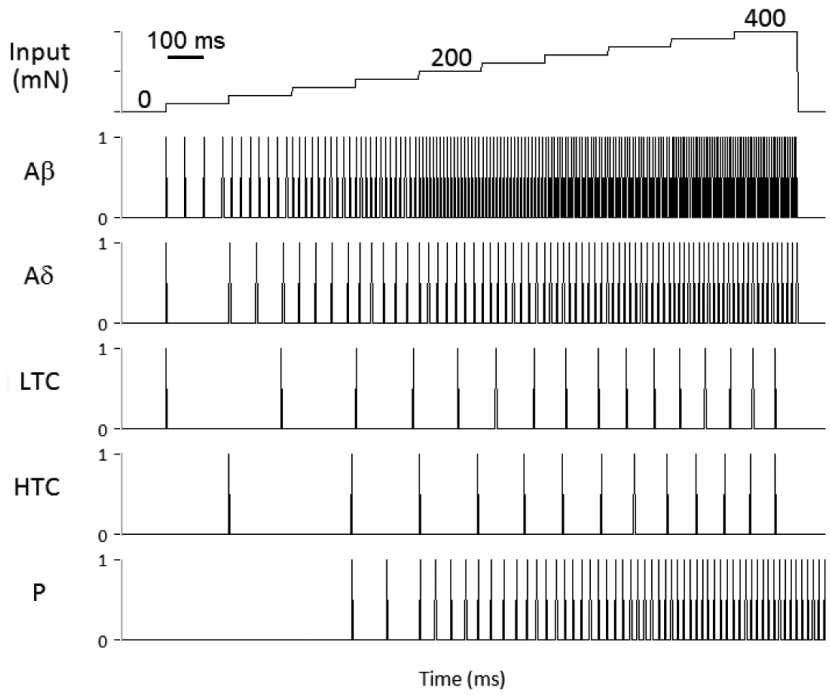

Figure 3. The response of the superficial dorsal horn (SDH) network-model to progressive increases of the stimulus amplitude. (a) The A $\beta$-, A $\delta$-, low-threshold C-Neuroid (LTC-Neuroid) and high-threshold C-Neuroid (HTC-Neuroid) are simultaneously stimulated to simulate co-activation of primary afferents. (b) Response of the A $\beta$-, A $\delta$-, LTC- and HTC-Neuroid and the lamina I projection-Neuroid (P-Neuroid) to gradual increases of stimulus amplitude. (c) The response of the P-Neuroid to gradual increases of the stimulus amplitude increases monotonically, as has been recently described for nociceptive specific projection neurons (Craig et al., 2001). 
(a)

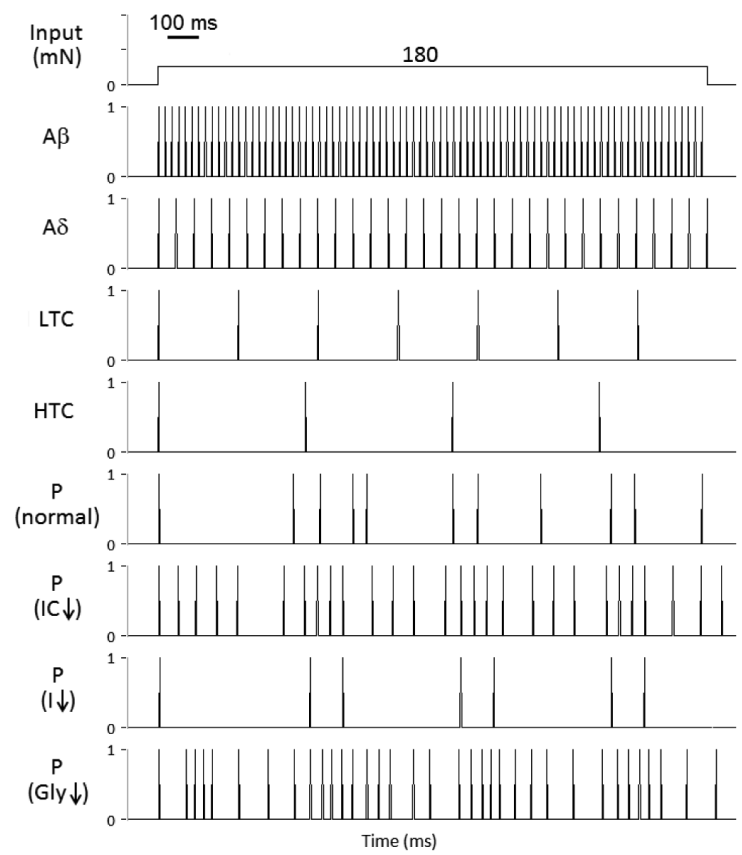

(c)

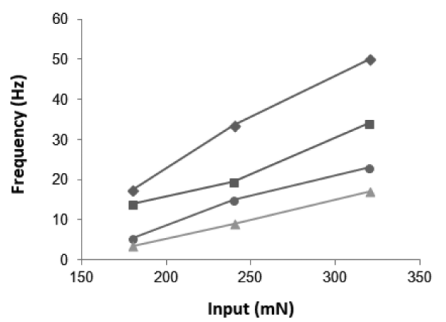

(b)

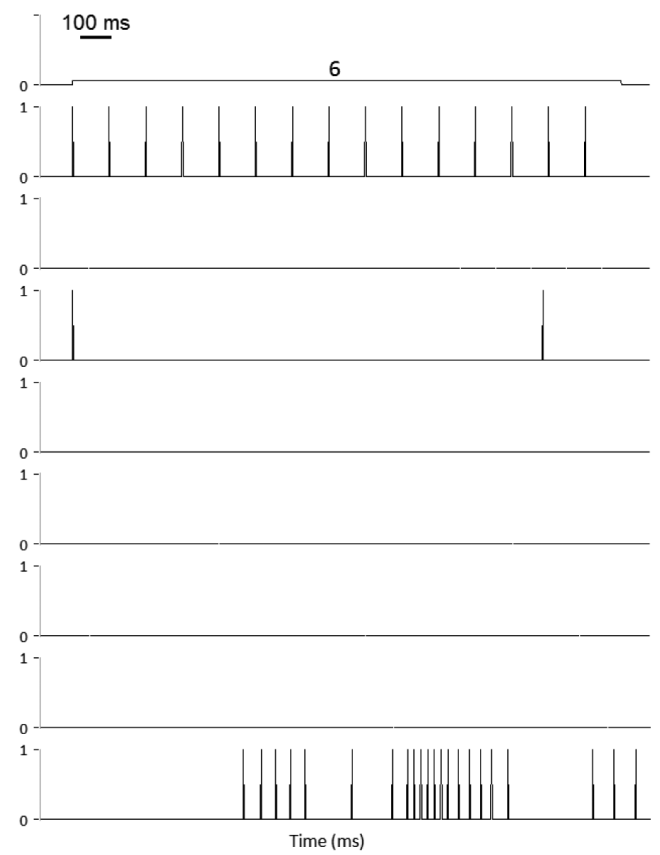

(d)

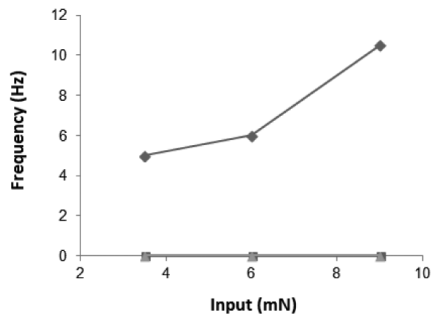

Figure 4. Regionally specific changes of the inhibitory tone may lead to different abnormal pain sensations. Reducing of the influence exerted by a specific Neuroid is represented by a downwards arrow ( $\downarrow$ ). (a) The response of the lamina I projection neuron-Neuroid (P-Neuroid) to "noxious" sustained stimulation increases when the inhibitory influence of the inhibitory central-Neuroid (IC-Neuroid; lamina II) and the glycinergic-Neuroid (Gly-Neuroid; lamina III) was diminished $\left(7^{\text {th }}\right.$ and $9^{\text {th }}$ panels from the top), but it decreases as a result of reduced inhibitory tone provided by the islet-Neuroid (I-Neuroid; lamina II) $\left(8^{\text {th }}\right.$ panel). (b) The P-Neuroid responds to "non-noxious" sustained stimulation only when the inhibitory influence of the Gly-Neuroid (lamina III) is diminished (9 $9^{\text {th }}$ panel). (c) and (d) The responsiveness of the P-Neuroid to "noxious" and "non-noxious" stimuli, respectively, with $100 \%$ of inhibitory control (dark gray circles) and after diminishing the inhibitory control exerted by the IC-Neuroid (dark gray squares), the I-Neuroid (light gray triangles) and the Gly-Neuroid (dark gray diamonds). The results suggest that inhibitory neurons from lamina III prevent innocuous stimuli access to nociceptive pathways, whereas inhibitory neurons from lamina II may be responsible for maintaining the proper level of pain sensitivity.

\section{Discussion}

The aims of this study were, essentially, to quantify the response of lamina I projection neurons to peripheral mechanical stimuli and to assess how different is that response after simulating regionally specific reduction of the inhibitory tone. We developed a computational model of the SDH circuitry by integrating fragmentary experimental evidence and we used Neuroids to simulate each neuron included in that model. Results suggest that lamina-specific disinhibition may lead to different abnormal pain sensations. In addition, the SDH network-model was able to capture non-linearities involved in pain processes, such as A $\beta$-fiber mediated analgesia and frequency-dependent increase of the neural response.

\section{The Neuroid as the main building block for the modeling of pain circuits}

At the single-cell level, we compared the individual response of some Neuroids with experimental observations. The comparison was subject to the 
(a)

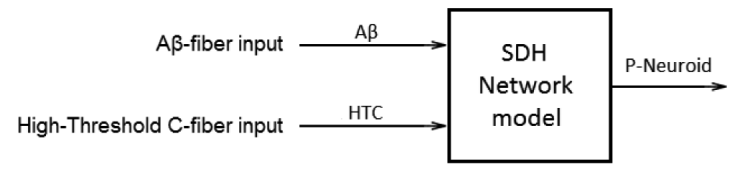

(b)

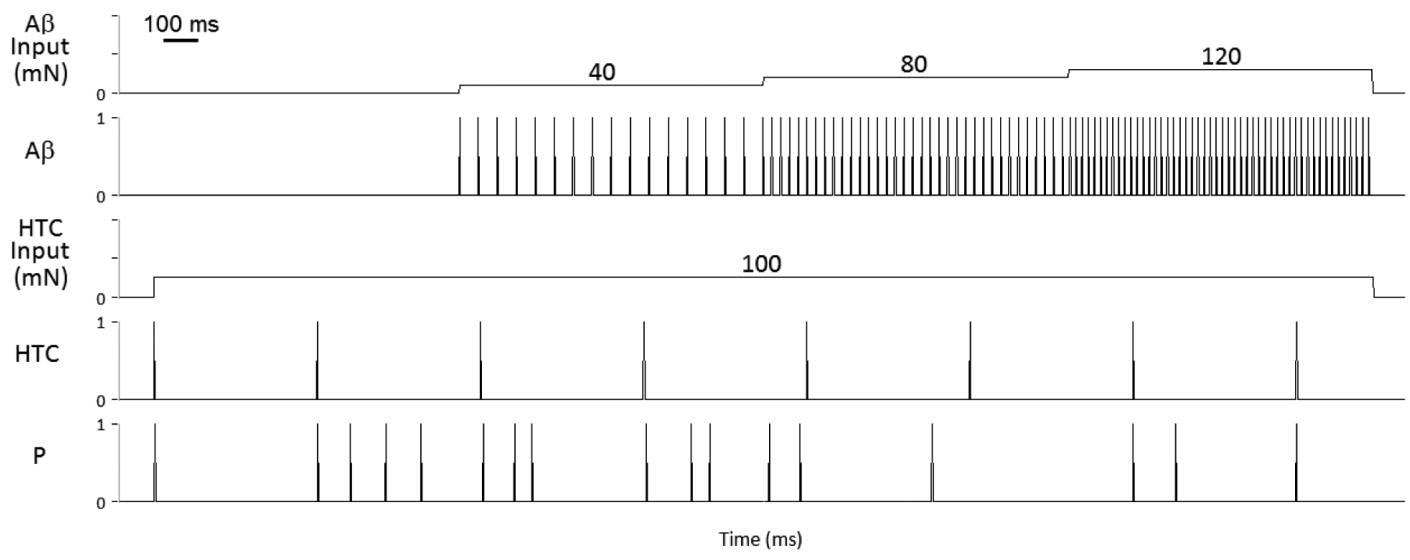

(c)

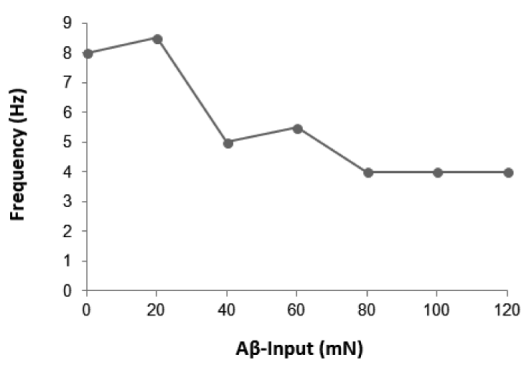

Figure 5. A $\beta$-fiber mediated analgesia. (a) Only the A $\beta$-Neuroid and the high-threshold C-Neuroid (HTC-Neuroid) are stimulated. (b) The response of the lamina I projection-Neuroid (P-Neuroid) slightly decreases ( $5^{\text {th }}$ panel) with an increasing A $\beta$-Neuroid input while the HTC-Neuroid input remains constant, as predicted by the Gate Control Theory (Melzack and Wall, 1965). (c) For A $\beta$-Neuroid inputs greater than $80 \mathrm{mN}$, the firing frequency of the P-Neuroid ceases to decrease, which suggests that the A $\beta$-mediated analgesia it is possible only within a limited range of mechanical (tactile) stimuli.

availability of data, which is why we did not compare the response of the $A \beta$-Neuroid with that exhibited by its biological counterpart (several groups (Cain et al., 2001; Slugg et al., 2000; 2004) have totalized the number of action potentials evoked as a function of mechanical stimulus intensity, but this characterization was restricted to thinly-myelinated/unmyelinated afferent neurons and no recent studies seem to be available to compare the FI curves of nociceptive and non-nociceptive primary afferents). It can be seen that the FI curve of the $\mathrm{A} \delta$-Neuroid matched the experimental curve (Figure 2c), whereas the FI curve of the HTC-Neuroid increased monotonically (Figure 2f) instead of reaching a plateau as reported previously by Slugg et al. (2000). However, in a subsequent study (Slugg et al., 2004), it was demonstrated that the average response of $\mathrm{C}$-fiber nociceptors across the receptive field does not reach a plateau, but increases monotonically with mechanical stimulus intensity. This suggests that the Neuroid might be used to predict the "average" response of a specific subpopulation of nociceptive primary afferents as long as the variability of experimental data is taken into account.

As stated before, the Neuroid is able to represent tonic-firing neurons. Interestingly, the majority of DH neurons fall into this class (Ruscheweyh and Sandkühler, 2002). On the other hand, experimental FI 
(a)

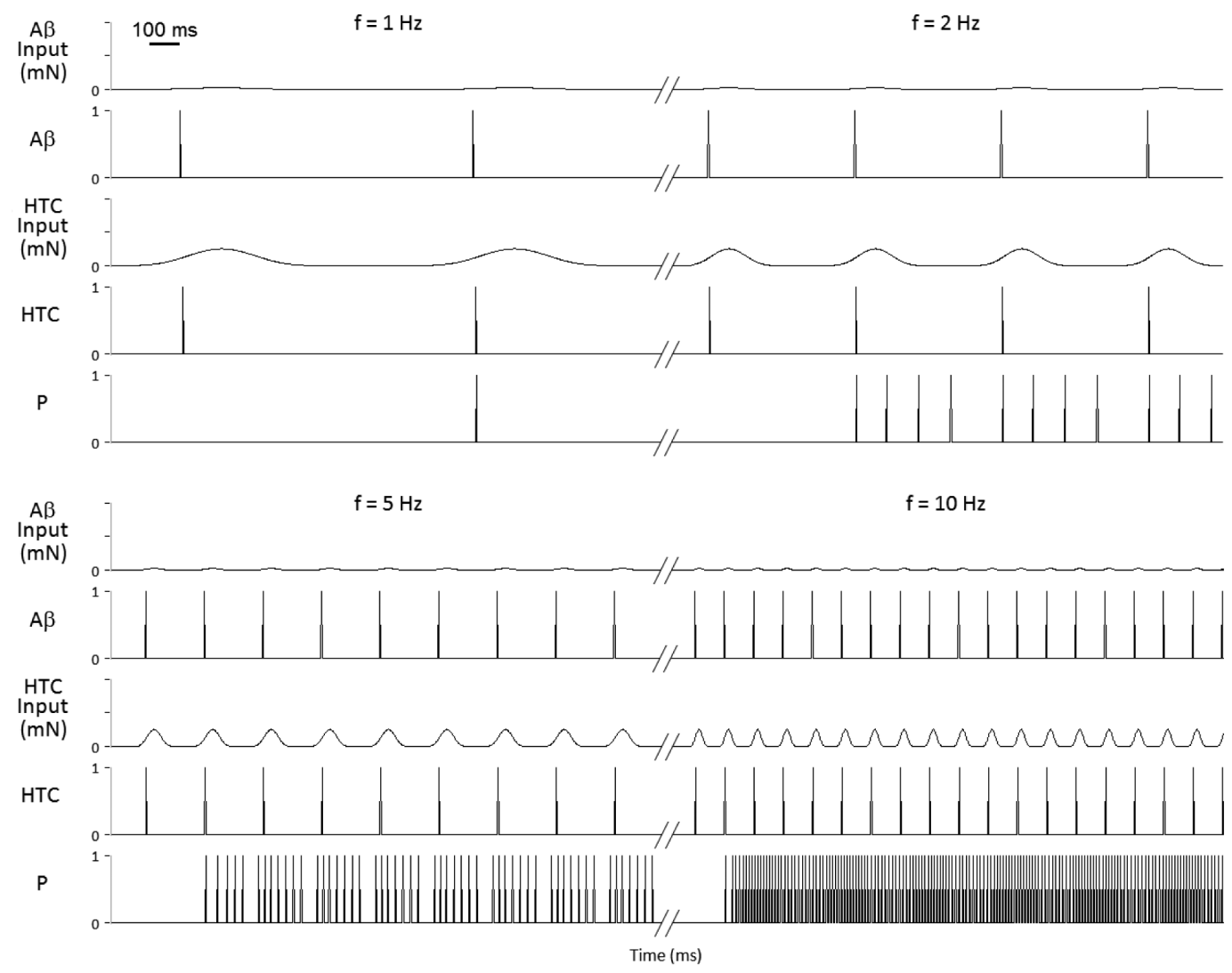

(b)

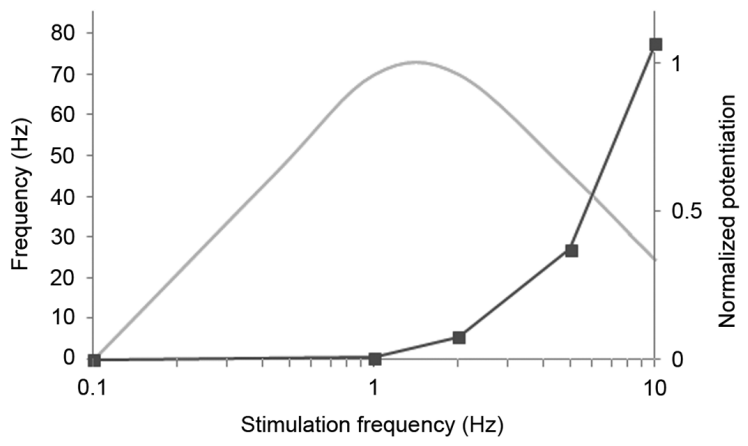

Figure 6. Frequency-dependent potentiation. (a) The firing frequency of the lamina I projection-Neuroid (P-Neuroid) increases vigorously $\left(5^{\text {th }}\right.$ panel) with the stimulation frequency, which resembles a potentiation that may be assumed as wind-up. (b) The response of the P-Neuroid (dark gray line, closed squares) seems to increase monotonically with the frequency of stimulation rather than describing an inverted " $U$ " (light gray line), as has been previously reported (Schouenborg, 1984).

curves of DH neurons tend to be pseudo-logarithmic rather than linear (Figures $2 \mathrm{k}, 1$ ), thereby suggesting that the Neuroid may fail to capture some important features of biological neurons and more detailed neuron models should be used as the main building block for the computational modeling of pain circuits, as done by several authors (Agi et al., 2010; Farajidavar et al., 2008; Xu et al., 2008). Nevertheless, it has been shown that computational properties of networks composed of simple (e.g. digital) neuron models are preserved in networks composed of more realistic building blocks (Hopfield, 1982; 1984). Hence, the Neuroid, a neuron model that reproduces the frequency modulationdemodulation process carried out by biological neurons (Bayly, 1968; Horch and Dhillon, 2004; Rieke et al., 1997), may be used in elucidating how biological neural networks perform their computations without expending time and energy on modeling a phenomenon 
(i.e. the generation of action potentials) that is already well understood. Furthermore, it was possible to reduce the inhibitory tone provided by a specific cell by manipulating just one parameter of that Neuroid $(\beta)$, thereby allowing us to focus both intellectual and computational resources on how the proposed circuit carries out its computations and how different is that result after simulating regionally specific reduction of the inhibitory tone. Computations carried out by sensory circuits (especially those located at spinal cord) have recently gained more attention (Prescott and Ratté, 2012; Prescott et al., 2014) in the light of new evidence pointing out that simultaneous activation of different primary afferent subpopulations may determine the resulting sensation (Ma, 2012), which in turns demands both definitive identification of the cells composing those circuits and a wiring diagram depicting how they are synaptically connected.

\section{An overview of the input-output relationship at the SDH}

As shown in Figure 3c, the response of the P-Neuroid to gradual increases of stimulus amplitude increased monotonically above $\sim 130 \mathrm{mN}$. This is consistent with experimental results (Andrew and Craig, 2002; Craig et al., 2001), although a more recent study points out that the response of nociceptive specific projection neurons resembles a sigmoid curve (Lavertu et al., 2014). On the other hand, the maximum firing frequency and thresholds predicted by the SDH network-model $(\sim 70 \mathrm{~Hz}$ and $\sim 130 \mathrm{mN}$ $=13.26 \mathrm{~g})$ were respectively much greater and much lower than experimental values $(8-20 \mathrm{~Hz}$ and 60-100 g) (Craig et al., 2001; Lavertu et al., 2014). Discrepancies may be attributed to differences in the experimental protocol used to quantify the response properties of primary afferent and dorsal horn neurons (current injection vs. peripheral stimuli; in vivo vs. in vitro). While Neuroids representing primary afferent neurons were configured according to the response of these cells to peripheral mechanical stimuli (Cain et al., 2001; Slugg et al., 2000, 2004), Neuroids representing dorsal horn neurons were configured according to the response of these cells to current injections (Ruscheweyh and Sandkühler, 2002), since no recent studies seem to be available to extract relevant features of the dorsal horn neurons responses to peripheral mechanical stimuli (e.g. the frequencyintensity curve). The problem arises from the fact that there is no direct relation between current-evoked and peripherally evoked responses of dorsal horn neurons (Graham et al., 2004). Furthermore, we did not consider the contribution of supraspinal structures (e.g. the rostral ventromedial medulla - RVM) to noxious spinal processing. So far, it is known that On- and Off-cells originating from the RVM act together, putatively, to facilitate the withdrawal response by amplifying the gain of the nociceptive spinal circuit (Mendell, 2011), but the question of whether On- and Off-cells target the same or different spinal neurons populations (e.g. vertical, islet, central) remains unanswered. Still, all these issues do not dismiss the fact that the network-model was able to capture the essential features of spinal processing; by contrast, they should encourage researchers to perform further research in this direction.

While pressure is important in determining pain response (Craig et al., 2001; Lavertu et al., 2014), force has also proved useful (Andrew and Craig, 2002). Pressure stimuli, by definition, distribute force over an area and, therefore, they are likely to activate different subpopulations of cutaneous receptors (Ma, 2012), an aspect that was modeled in this study by simultaneously activating afferent Neuroids (Figure 3a). On the contrary, previous work on the computational modeling of pain (Agi et al., 2010; Britton et al., 1996; Prince et al., 2004) has focused on using different inputs designed for each type of afferent fiber instead of co-activation. This may seriously limit our understanding on how sensory information conveyed by different populations of primary afferents is processed by spinal circuits, given that interactions between different pathways may be overlooked unless multiple inputs are co-activated, as done in the present study.

\section{Regionally specific subpopulations of SDH neurons may prevent one specific neuropathic condition}

In order to provide a valuable tool for mapping inhibitory tone in pain pathways, we simulated lamina-specific reduction of inhibitory control during "noxious" and "non-noxious" sustained stimulation (Figures 4a, b). As a result, the response of the P-Neuroid to "noxious" stimulation had an increase of $\sim 17$ and $\sim 78 \%$ when the inhibitory influence exerted by the IC- (lamina II) and Gly-Neuroids (lamina III), respectively, was significantly reduced $(50 \%)$, but it had a decrease of $\sim 14 \%$ when the inhibitory tone provided by the I-Neuroid (lamina II) was reduced in the same proportion (Figure 4c). The latter apparently contradicts previous studies arguing that loss of inhibitory control at lamina II may lead to abnormal pain sensations (Meisner et al., 2010; Takazawa and MacDermott, 2010b). However, it can be seen from Figure 1 that inhibition of the I-Neuroid (which represents the islet cell reported by Lu and Perl (2003)) "disinhibits" the IC-Neuroid (the inhibitory central cell reported by Zheng et al. (2010)), which in turn inhibits the afferent input from the $\mathrm{A} \delta$-Neuroid to the 
vertical cell-Neuroid (V-Neuroid), thereby resulting in a diminished response of the P-Neuroid. It suggests that reciprocal inhibitory linkages at lamina II may regulate not only cross-modal interactions between inputs from different subpopulations of primary afferents, but also the proper level of pain sensitivity by a very fine tuning mechanism.

Conversely, the P-Neuroid responded to "nonnoxious" stimulation only after reducing by $50 \%$ the inhibitory tone provided by the Gly-Neuroid (which represents a glycinergic neuron in lamina III, in agreement with previous studies (Inquimbert et al., 2007; Takazawa and MacDermott, 2010a) (Figure 4d). This result together with the aforementioned increase of the P-Neuroid response to "noxious" stimuli when the inhibitory influence of the Gly-Neuroid was diminished in the same proportion, suggests that inhibitory neurons in lamina III are responsible for keeping the nociceptive pathway separated from the mechanoreceptive pathway. This is consistent with the statement that $A \beta$-fiber endings innervate exclusively the deeper laminae (III-V) (Millán, 1999; Todd, 2010) and information conveyed by this fibers can only gain access to nociceptive specific projection neurons in lamina I through polysynaptic pathways (Lu et al., 2013; Miraucourt et al., 2007). There is some evidence supporting the existence of a monosynaptic excitatory linkage between A $\beta$-fibers and lamina II vertical cells that project their dendrites toward deeper laminae (Kato et al., 2009; Kosugi et al., 2013), but a more recent study argues that distal input could be insufficient to activate vertical cells (Yasaka et al., 2014).

The idea of a regionally specific inhibitory control at spinal level has been proposed before (Takazawa and MacDermott, 2010a; 2010b). Unfortunately, there is little evidence to support this theory. An experimental study performed by Cronin et al. (2004) showed that pharmacological blockade of tonic GABAergic inhibition in the SDH (simulated by reducing the inhibitory tone provided by the I- and IC-Neuroids) may underlie hypersensitivity to noxious stimuli (hyperalgesia), whereas pharmacological blockade of glycinergic inhibition (simulated by reducing the inhibitory tone provided by the Gly-Neuroid), which is more dominant at deeper laminae, is able to provoke hypersensitivity to low intensity stimuli (allodynia). Our results are consistent with those observations, but further work is needed to prove that a regionally specific subpopulation of SDH neurons may prevent one specific neuropathic condition. If this is so, lamina-specific therapeutic alternatives could be designed for effective treatment of different abnormal pain sensations.

\section{Non-linearities in noxious stimuli processing}

As originally predicted by the Gate Control Theory (GCT), tactile stimuli are able to suppress nociceptive transmission at spinal level via a gating mechanism provided by lamina II inhibitory neurons (Melzack and Wall, 1965). This A $\beta$-fiber mediated analgesic effect has been replicated by computational models, all of them based on the GCT (Agi et al., 2010; Britton et al., 1996; Prince et al., 2004). But the architecture of our SDH network-model is quite different. Nevertheless, the model was able to preserve one of the most important postulates of the GCT, since the firing frequency of the P-Neuroid decreased by $50 \%$ after the $A \beta$-fiber input reached $80 \mathrm{mN}$, as shown in Figure $5 \mathrm{~b}\left(4^{\text {th }}\right.$ panel $)$. Above this value, the response of the P-Neuroid remained unaffected, thereby suggesting that the $A \beta$-mediated analgesia it is possible only within a limited range of mechanical (tactile) stimuli as we hypothesized in a previous work (Prada and Bustillos, 2013). Moreover, the P-Neuroid responded to amplitudes lower than $130 \mathrm{mN}$ (the predicted threshold under co-stimulation regime) when no stimulus was applied to the A $\beta$-Neuroid (Figure 5b; first $800 \mathrm{~ms}$ ). As depicted in Figure 1, the $A \beta$-fiber mediated analgesia is provided by the IC-Neuroid, representing an inhibitory central cell (Zheng et al., 2010), which can be found throughout the lamina II and whose branches often extend to lamina I or III (Yasaka et al., 2010), so it is likely to receive input from $\mathrm{A} \beta$-fibers. However, those inhibitory neurons may also receive inputs from HT primary afferents (Daniele and MacDermott, 2009). Likewise, some of these neurons are more likely to receive inputs from unmyelinated fibers particularly associated to cooling receptors (Zheng et al., 2010). This information can be included in future versions of the SDH network-model to elucidate how crossmodal interactions contribute to pain processing and, ultimately, perception.

The vigorous increase of the number of action potentials fired by the P-Neuroid as a response to repetitive stimulation at frequencies greater than $2 \mathrm{~Hz}$ (Figure 6a), resembled a potentiation that can be assumed as wind-up, a frequency-dependent increase of the DH neurons excitability evoked by recurrent stimulation of nociceptive primary afferents (Herrero et al., 2000) which has been successfully reproduced by computational models at the level of artificial neural networks (Haeri et al., 2003) as well as at the cellular and molecular level (Britton et al., 1996; Farajidavar et al., 2008). Nevertheless, wind-up only occurs within a narrow band of frequencies of stimulation and it reaches its maximum around $1-2 \mathrm{~Hz}$ (Schouenborg, 1984) (see Figure 6b). In addition, experimental data usually exhibit a slower increase 
in firing over several stimuli. On the contrary, the response of the P-Neuroid was highest after the second stimulus and it appeared to increase monotonically with the frequency of stimulation. Finally, since our main building block does not take into account $\mathrm{N}$-methylD-aspartate (NMDA) receptor-mediated transmission and/or intrinsic mechanisms like calcium activated currents, the frequency-dependent potentiation of the P-Neuroid response is not consistent with the current definition of wind-up. Still, this leaves open the question of whether stimulation frequency may determine the response properties of Neuroid-based networks.

Given the importance of the SDH as the first node of the pain pathway, several efforts have been made to unravel the underlying neural circuitry. Due to the extremely complex cytoarchitecture of that region as well as the technical difficulties of performing electrophysiological recordings from those neurons, delineating the SDH connectivity patterns has proven to be a challenging task. Results provided by this study suggest that by integrating the fragments of neuroanatomical information provided by different work groups, it would be possible to aid in understanding how those patterns contribute to noxious transmission in either physiological or pathological conditions. Both the Neuroid and the SDH network-model have their limits, either because the main building block cannot capture all features of biological neurons or because the network does not include most recent neuroanatomical findings. Still, this work can be extended by incorporating biophysical accuracy and newer experimental evidence, which is, certainly, the ultimate goal of the present study.

\section{Acknowledgements}

The lead author thanks Prof. Antonio D'Alessandro Martínez for his valuable ideas and useful observations during the realization of this article.

\section{References}

Agi E, Ozgen C, Purali N. Modeling of gate control neuronal circuitry including morphologies and physiologies of component neurons and fibres. In: Kothare MV, Tade MO, Vande Wouwer A, Smets I, editors. Proceedings of the 9th International Symposium on Dynamics and Control of Process Systems; 2010 Jul 5-7; Leuven, Belgium. Leuven: International Federation of Automatic Control; 2010. p. 857-62.

Andrew D, Craig AD. Responses of spinothalamic lamina I neurons to maintained noxious mechanical stimulation in the cat. Journal of Neurophysiology. 2002; 87(4):1889-901. PMid:11929909.

Baba H, Doubell TP, Woolf CJ. Peripheral inflammation facilitates Abeta fiber-mediated synaptic input to the substantia gelatinosa of the adult rat spinal cord. The Journal of Neuroscience: The Official Journal of the Society for Neuroscience. 1999; 19(2):859-67. PMid:9880605.

Baba H, Ji RR, Kohno T, Moore KA, Ataka T, Wakai A, Okamoto M, Woolf CJ. Removal of GABAergic inhibition facilitates polysynaptic A fiber-mediated excitatory transmission to the superficial spinal dorsal horn. Molecular and Cellular Neurosciences. 2003; 24(3):818-30. http://dx.doi.org/10.1016/ S1044-7431(03)00236-7. PMid:14664828.

Bayly EJ. Spectral analysis of pulse frequency modulation in the nervous systems. IEEE Transactions on Biomedical Engineering. 1968; 15(4):257-65. http://dx.doi.org/10.1109/ TBME.1968.4502576. PMid:5699902.

Britton NF, Chaplain MAJ, Skevington SM. The role of N-methyl-D-aspartate (NMDA) receptors in wind-up: a mathematical model. IMA Journal of Mathematics Applied in Medicine and Biology. 1996; 13(3):193-205. http://dx.doi. org/10.1093/imammb/13.3.193. PMid:8921589.

Cain DM, Khasabov SG, Simone DA. Response properties of mechanoreceptors and nociceptors in mouse glabrous skin: an in vivo study. Journal of Neurophysiology. 2001; 85(4):1561-74. PMid:11287480.

Callaway EM, Katz LC. Photostimulation using caged glutamate reveals functional circuitry in living brain slices. Proceedings of the National Academy of Sciences of the United States of America. 1993; 90(16):7661-5. http://dx.doi. org/10.1073/pnas.90.16.7661. PMid:7689225.

Costigan M, Scholz J, Woolf CJ. Neuropathic pain: a maladaptive response of the nervous system to damage. Annual Review of Neuroscience. 2009; 32(1):1-32. http://dx.doi.org/10.1146/annurev.neuro.051508.135531. PMid:19400724.

Craig AD, Krout K, Andrew D. Quantitative response characteristics of thermoreceptive and nociceptive lamina I spinothalamic neurons in the cat. Journal of Neurophysiology. 2001; 86(3):1459-80. PMid:11535691.

Cronin JN, Bradbury EJ, Lidierth M. Laminar distribution of GABAA- and glycine-receptor mediated tonic inhibition in the dorsal horn of the rat lumbar spinal cord: effects of picrotoxin and strychnine on expression of Fos-like immunoreactivity. Pain. 2004; 112(1-2):156-63. http:// dx.doi.org/10.1016/j.pain.2004.08.010. PMid:15494196.

Daniele CA, MacDermott AB. Low-threshold primary afferent drive onto GABAergic interneurons in the superficial dorsal horn of the mouse. The Journal of Neuroscience. 2009; 29(3):686-95. http://dx.doi.org/10.1523/ JNEUROSCI.5120-08.2009. PMid:19158295.

Farajidavar A, Saeb S, Behbehani K. Incorporating synaptic time-dependent plasticity and dynamic synapse into a computational model of wind-up. Neural Networks: The Official Journal of the International Neural Network Society. 2008; 21(2-3):241-9. http://dx.doi.org/10.1016/j. neunet.2007.12.021. PMid:18242953.

Graham BA, Brichta AM, Callister RJ. In vivo responses of mouse superficial dorsal horn neurones to both current injection and peripheral cutaneous stimulation. The Journal of Physiology. 2004; 561(3):749-63. http://dx.doi.org/10.1113/ jphysiol.2004.072645. PMid:15604230.

Graham BA, Brichta AM, Callister RJ. Moving from an averaged to specific view of spinal cord pain processing 
circuits. Journal of Neurophysiology. 2007; 98(3):1057-63. http://dx.doi.org/10.1152/jn.00581.2007. PMid:17567772.

Haeri M, Asemani D, Gharibzadeh S. Modeling of pain using artificial neural networks. Journal of Theoretical Biology. 2003; 220(3):277-84. http://dx.doi.org/10.1006/ jtbi.2003.3130. PMid:12468280.

Herrero JF, Laird JM, López-García JA. Wind-up of spinal cord neurones and pain sensation: much ado about something? Progress in Neurobiology. 2000; 61(2):169-203. http://dx.doi. org/10.1016/S0301-0082(99)00051-9. PMid:10704997.

Hopfield JJ. Neural networks and physical systems with emergent collective computational abilities. Proceedings of the National Academy of Sciences of the United States of America. 1982; 79(8):2554-8. http://dx.doi.org/10.1073/ pnas.79.8.2554. PMid:6953413.

Hopfield JJ. Neurons with graded response have collective computational properties like those of two-state neurons. Proceedings of the National Academy of Sciences of the United States of America. 1984; 81(10):3088-92. http:// dx.doi.org/10.1073/pnas.81.10.3088. PMid:6587342.

Horch KW, Dhillon GS. Neuroprosthetics: theory and practice. New York: World Scientific; 2004.

Inquimbert P, Rodeau JL, Schlichter R. Differential contribution of GABAergic and glycinergic components to inhibitory synaptic transmission in lamina II and laminae III-IV of the young rat spinal cord. The European Journal of Neuroscience. 2007; 26(10):2940-9. http://dx.doi. org/10.1111/j.1460-9568.2007.05919.x. PMid:18001289.

Kato G, Kawasaki Y, Koga K, Uta D, Kosugi M, Yasaka T, Yoshimura M, Ji RR, Strassman AM. Organization of intralaminar and translaminar neuronal connectivity in the superficial spinal dorsal horn. The Journal of Neuroscience. 2009; 29(16):5088-99. http://dx.doi.org/10.1523/ JNEUROSCI.6175-08.2009. PMid:19386904.

Keller AF, Beggs S, Salter MW, De Koninck Y. Transformation of the output of spinal lamina I neurons after nerve injury and microglia stimulation underlying neuropathic pain. Molecular Pain. 2007; 3(1):27. http://dx.doi.org/10.1186/1744-80693-27. PMid:17900333.

Kosugi M, Kato G, Lukashov S, Pendse G, Puskar Z, Kozsurek M, Strassman AM. Subpopulation-specific patterns of intrinsic connectivity in mouse superficial dorsal horn as revealed by laser scanning photostimulation. The Journal of Physiology. 2013; 591(7):1935-49. http://dx.doi.org/10.1113/ jphysiol.2012.244210. PMid:23297304.

Lavertu G, Côté SL, De Koninck Y. Enhancing K-Cl cotransport restores normal spinothalamic sensory coding in a neuropathic pain model. Brain. 2014; 137(3):724-38. http://dx.doi.org/10.1093/brain/awt334. PMid:24369380.

Lu Y, Dong H, Gao Y, Gong Y, Ren Y, Gu N, Zhou S, Xia N, Sun YY, Ji RR, Xiong L. A feed-forward spinal cord glycinergic neural circuit gates mechanical allodynia. The Journal of Clinical Investigation. 2013; 123(9):4050-62. http://dx.doi.org/10.1172/JCI70026. PMid:23979158.

Lu Y, Perl ER. A specific inhibitory pathway between substantia gelatinosa neurons receiving direct $\mathrm{C}$-fiber input. The Journal of Neuroscience: The Official Journal of the Society for Neuroscience. 2003; 23(25):8752-8. PMid:14507975.
Lu Y, Perl ER. Modular organization of excitatory circuits between neurons of the spinal superficial dorsal horn (laminae I and II). The Journal of Neuroscience 2005; 25(15):39007. http://dx.doi.org/10.1523/JNEUROSCI.0102-05.2005. PMid:15829642.

Ma Q. Population coding of somatic sensations. Neuroscience Bulletin. 2012; 28(2):91-9. http://dx.doi.org/10.1007/ s12264-012-1201-2. PMid:22466120.

Meisner JG, Marsh AD, Marsh DR. Loss of GABAergic interneurons in laminae I-III of the spinal cord dorsal horn contributes to reduced GABAergic tone and neuropathic pain after spinal cord injury. Journal of Neurotrauma. 2010; 27(4):729-37. http://dx.doi.org/10.1089/neu.2009.1166. PMid:20059302.

Melzack R, Wall PD. Pain mechanisms: a new theory. Science 1965; 150(3699):971-9. http://dx.doi.org/10.1126/ science.150.3699.971. PMid:5320816.

Mendell LM. Computational functions of neurons and circuits signaling injury: relationship to pain behavior. Proceedings of the National Academy of Sciences of the United States of America. 2011; 108(Suppl 3):15596-601. http://dx.doi. org/10.1073/pnas.1012195108. PMid:21368123.

Millán MJ. The induction of pain: an integrative review. Progress in Neurobiology. 1999; 57(1):1-164. http://dx.doi. org/10.1016/S0301-0082(98)00048-3. PMid:9987804.

Miraucourt LS, Dallel R, Voisin DL. Glycine inhibitory dysfunction turns touch into pain through PKCgamma interneurons. PLoS One. 2007; 2(11):e1116. http://dx.doi. org/10.1371/journal.pone.0001116. PMid:17987109.

Polgár E, Durrieux C, Hughes DI, Todd AJ. A quantitative study of inhibitory interneurons in laminae I-III of the mouse spinal dorsal horn. PLoS One. 2013; 8(10):e78309. http:// dx.doi.org/10.1371/journal.pone.0078309. PMid:24205193.

Prada EJA, Bustillos RJS, Castillo C, Huerta M. New trends in computational modeling: a neuroid-based retina model. In: Proceedings of the 35th Annual International Conference of the IEEE, Engineering in Medicine and Biology Society (EMBC); 2013 Jul 3-7; Osaka, Japan. Osaka: IEEE; 2013. p. 4561-4.

Prada EJA, Bustillos RJS, Castillo C, Huerta M. The neuroid: a novel and simplified neuron-model. In: Proceedings of the 34th Annual International Conference of the IEEE, Engineering in Medicine and Biology Society (EMBC); 2012 Aug 28-Sep 1; San Diego, CA. San Diego: IEEE; 2012. p. 1234-7.

Prada EJA, Bustillos RJS. The implementation of the neuroid in the gate control system leads to new ideas about pain processing. Revista Brasileira de Engenharia Biomédica. 2013; 29(3):254-61.

Prescott SA, Ma Q, De Koninck Y. Normal and abnormal coding of somatosensory stimuli causing pain. Nature Neuroscience. 2014; 17(2):183-91. http://dx.doi.org/10.1038/ nn.3629. PMid:24473266.

Prescott SA, Ratté S. Pain processing by spinal microcircuits: afferent combinatorics. Current Opinion in Neurobiology. 2012; 22(4):631-9. http://dx.doi.org/10.1016/j.conb.2012.02.010. PMid:22409855.

Prince KM, Campbell J, Picton P, Turner S. A computational model of acute pain. In: Horton G. Proceedings of the 18th 
European Simulation Multiconference; 2004 Jun 13-16; Magdeburg, Germany. Magdeburg: SCS Europe; 2004.

Rieke F, Warland D, van Steveninck RR, Bialek W. Spikes: exploring the neural code. Cambridge: MIT Press; 1997.

Ruscheweyh R, Sandkühler J. Lamina-specific membrane and discharge properties of rat spinal dorsal horn neurones in vitro. The Journal of Physiology. 2002; 541(1):231-44. http:// dx.doi.org/10.1113/jphysiol.2002.017756. PMid:12015432.

Sandkühler J. Models and mechanisms of hyperalgesia and allodynia. Physiological Reviews. 2009; 89(2):707-58. http:// dx.doi.org/10.1152/physrev.00025.2008. PMid:19342617.

Schoffnegger D, Ruscheweyh R, Sandkühler J. Spread of excitation across modality borders in spinal dorsal horn of neuropathic rats. Pain. 2008; 135(3):300-10. http://dx.doi. org/10.1016/j.pain.2007.12.016. PMid:18262362.

Schouenborg J. Functional and topographical properties of field potentials evoked in rat dorsal horn by cutaneous C-fibre stimulation. The Journal of Physiology. 1984; 356(1):169-92. http://dx.doi.org/10.1113/jphysiol.1984. sp015459. PMid:6520786.

Slugg RM, Campbell JN, Meyer RA. The population response of $\mathrm{A}$ - and $\mathrm{C}$-fiber nociceptors in monkey encodes high-intensity mechanical stimuli. The Journal of Neuroscience. 2004; 24(19):4649-56. http://dx.doi. org/10.1523/JNEUROSCI.0701-04.2004. PMid:15140936.

Slugg RM, Meyer RA, Campbell JN. Response of cutaneous $\mathrm{A}$ - and C-fiber nociceptors in the monkey to controlled-force stimuli. Journal of Neurophysiology. 2000; 83(4):2179-91. PMid:10758127.

Takazawa T, MacDermott AB. Glycinergic and GABAergic tonic inhibition fine tune inhibitory control in regionally distinct subpopulations of dorsal horn neurons. The Journal of Physiology. 2010a; 588(14):2571-87. http://dx.doi. org/10.1113/jphysiol.2010.188292. PMid:20498232.

Takazawa T, MacDermott AB. Synaptic pathways and inhibitory gates in the spinal cord dorsal horn. Annals of the New York Academy of Sciences. 2010b; 1198(1):1538. http://dx.doi.org/10.1111/j.1749-6632.2010.05501.x. PMid:20536929.
Tamamaki N, Yanagawa Y, Tomioka R, Miyazaki J, Obata $\mathrm{K}$, Kaneko T. Green fluorescent protein expression and colocalization with calretinin, parvalbumin, and somatostatin in the GAD67-GFP knock-in mouse. The Journal of Comparative Neurology. 2003; 467(1):60-79. http://dx.doi org/10.1002/cne.10905. PMid:14574680.

Todd AJ, Sullivan AC. Light microscope study of the coexistence of GABA-like and glycine-like immunoreactivities in the spinal cord of the rat. The Journal of Comparative Neurology. 1990; 296(3):496-505. http://dx.doi.org/10.1002/ cne.902960312. PMid:2358549.

Todd AJ. Neuronal circuitry for pain processing in the dorsal horn. Nature Reviews. Neuroscience. 2010; 11(12):823-36. http://dx.doi.org/10.1038/nrn2947. PMid:21068766.

$\mathrm{Xu}$ F, Lu TJ, Seffen KA. Skin thermal pain modeling - a holistic method. Journal of Thermal Biology. 2008; 33(4):22337. http://dx.doi.org/10.1016/j.jtherbio.2008.01.004.

Yasaka T, Tiong SY, Hughes DI, Riddell JS, Todd AJ. Populations of inhibitory and excitatory interneurons in lamina II of the adult rat spinal dorsal horn revealed by a combined electrophysiological and anatomical approach. Pain. 2010; 151(2):475-88. http://dx.doi.org/10.1016/j. pain.2010.08.008. PMid:20817353.

Yasaka T, Tiong SY, Polgár E, Watanabe M, Kumamoto E, Riddell JS, Todd AJ. A putative relay circuit providing low-threshold mechanoreceptive input to lamina I projection neurons via vertical cells in lamina II of the rat dorsal horn. Molecular Pain. 2014; 10(1):3. http://dx.doi.org/10.1186/17448069-10-3. PMid:24433581.

Zeilhofer HU, Wildner H, Yévenes GE. Fast synaptic inhibition in spinal sensory processing and pain control. Physiological Reviews. 2012; 92(1):193-235. http://dx.doi. org/10.1152/physrev.00043.2010. PMid:22298656.

Zheng J, Lu Y, Perl ER. Inhibitory neurones of the spinal substantia gelatinosa mediate interaction of signals from primary afferents. The Journal of Physiology. 2010; 588(12):206575. http://dx.doi.org/10.1113/jphysiol.2010.188052. PMid:20403977.

\footnotetext{
Authors

Erick Javier Argüello Prada ${ }^{1 *}$, Ricardo José Silva Bustillos ${ }^{2,3}$, Mónica Karel Huerta ${ }^{4,5}$, Antonio D’Alessandro Martínez

${ }^{1}$ Laboratorio "C", Universidad Simón Bolívar, Caracas, Venezuela.

${ }^{2}$ Secretaría de Educación Superior, Ciencia, Tecnología e Innovación - SENESCYT, Universidad Politécnica Salesiana de Guayaquil, Guayaquil, Ecuador.

${ }^{3}$ Programa Promeinfo, Guayaquil, Ecuador.

${ }^{4}$ Universidad Politécnica Salesiana de Cuenca, Cuenca, Ecuador.

${ }^{5}$ Grupo de Redes y Telemática Aplicada, Universidad Simón Bolívar, Caracas, Venezuela.

${ }^{6}$ Instituto de Medicina Experimental, Facultad de Medicina, Cátedra de Fisiología, Universidad Central de Venezuela, Caracas, Venezuela.
} 